\title{
DNA typing of methicillin-resistant Staphylococcus aureus: isolates and factors associated with nosocomial acquisition in two Brazilian university hospitals
}

\author{
KÁTIA R. N. SANTOS*, LÚCIA M. TEIXEIRA, G. S. LEAL†, LEILA S. FONSECA and \\ P. P. GONTIJO FILHO† \\ Departamento de Microbiologia Médica, Instituto de Microbiologia, Universidade Federal do Rio de Janeiro, \\ RJ; * Departamento de Patologia, Universidade Federal do Mato Grosso do Sul, MS and †Departamento de \\ Patologia, Universidade Federal de Uberlândia, MG, Brasil
}

\begin{abstract}
Control and prevention of methicillin-resistant Staphylococcus aureus (MRSA) infections should include early identification of patients at higher risk of MRSA acquisition and analysis of isolates by discriminatory bacterial DNA typing methods. One hundred and three MRSA isolates cultured between Sept. 1994 and Sept. 1995 from 62 patients in two teaching hospitals (hospital 1, in Rio de Janeiro; hospital 2, in Minas Gerais) were tested for antimicrobial resistance and genomic DNA was analysed by pulsed-field gel electrophoresis (PFGE). Ten profiles were identified: $A, B, C, I$ and $J$ in hospital 1 and $A, B, D, E, F, G$ and $H$ in hospital 2. PFGE patterns $A$ and $B$ were isolated at both hospitals. The majority $(\mathbf{8 0} \%)$ of isolates had similar PFGE patterns (type A). Subtype $A_{1}$ was isolated at both hospitals, but was more frequent in hospital $2(54 \%)$, while subtype $A_{2}$ predominated in hospital $1(63 \%)$. MRSA isolates were resistant to the majority of antimicrobial agents tested. However, susceptibility to vancomycin alone was found in $32 \%$ of the isolates at hospital 1 , whereas $48 \%$ of isolates from hospital 2 were susceptible to both vancomycin and mupirocin, and $34 \%$ demonstrated susceptibility to vancomycin, mupirocin and chloramphenicol. Thirty-nine percent of all isolates were mupirocin-resistant, with $\mathbf{9 0 \%}$ of these belonging to PFGE pattern A. Four main risk factors were associated with MRSA infection or colonisation which may be useful in the early identification of patients at risk: $>7$ days hospitalisation $(95 \%)$, very dependent patients $(84 \%)$, invasive procedures $(79 \%)$ and recent antimicrobial therapy $(79 \%)$. The data demonstrate that PFGE pattern $A$ is disseminated in both hospitals. However, at both hospitals subtypes of pattern $A$ and the other PFGE types were associated with different antibiotic resistance patterns.
\end{abstract}

\section{Introduction}

Methicillin-resistant Staphylococcus aureus (MRSA) has been detected in the majority of tertiary hospitals and is responsible for an increasing number of nosocomial infections [1]. In institutions where MRSA is highly endemic, c. $1 \%$ of patients become colonised, and of these, $30-60 \%$ become infected with MRSA [2]. The percentage of MRSA in US hospitals ranged from $15 \%$ to $45 \%$ in 1991 , as reported to the NNIS System [3]. By 1990, MRSA strains represented 38-

Received 5 Jan. 1998; revised version received 24 March 1998; accepted 9 April 1998.

Corresponding author: Dr K. R. N. dos Santos.
$78 \%$ of all $S$. aureus strains isolated in tertiary hospitals in Brazil [4].

Effective control measures for reducing the hospital reservoir of MRSA depend initially on knowing the risk factors of the exposed population for MRSA acquisition [5]. Risk factors associated with nosocomial acquisition of MRSA include prolonged hospitalisation, preceding antimicrobial therapy, use of invasive procedures, treatment in an intensive care unit or a burns unit, surgical procedures and close proximity to a patient colonised or infected with MRSA [6]. Furthermore, Issa et al. [7] reported that heavy dependency, i.e., patients requiring considerable nursing and other support is another risk factor that should be considered. 
Control and prevention of MRSA infection or colonisation may include analysis of isolates by discriminatory bacterial DNA typing. Typing can be used to confirm or refute the relatedness of isolates and to plan MRSA control programmes [8]. Several investigators have demonstrated the superiority of macrorestriction analysis by pulsed-field gel electrophoresis (PFGE) for strain characterisation, when compared with other techniques $[9,10]$. This method provides highly reproducible restriction profiles that typically show distinct, well-resolved fragments representing the entire bacterial chromosome.

The aims of the present study were (1) to identify and compare the risk factors associated with nosocomial acquisition of MRSA colonisation or infection at two Brazilian university hospitals, and (2) to type MRSA isolates from patients by PFGE to identify clonal profiles associated with each hospital.

\section{Patients and methods}

\section{Setting}

The Rio de Janeiro Federal University Hospital (hospital 1) and the Uberlândia Federal University Hospital, Minas Gerais (hospital 2) are 350-bed, teaching hospitals providing tertiary care. The hospitals are located at $1000 \mathrm{~km}$ distance from each other and therefore physicians and other health care providers do not work in both hospitals.

\section{Laboratory methods}

Strains. All MRSA isolates from patients in both hospitals between Sept. 1994 and Sept. 1995 were included in the study. One hundred and three MRSA isolates from 62 patients were available for testing. Fifty-nine were isolated from hospital 1 and 44 from hospital 2. MRSA was isolated from surgical site infections $(13 \%)$, bloodstream infections $(11 \%)$, respiratory tract infections $(10 \%)$, abdominal cavity infections $(4 \%)$, urinary tract infections $(3 \%)$ and from colonised patients: anterior nares $37 \%$, rectal and perineal sites $13 \%$, skin lesions $9 \%$ and from tracheostomy sites $2 \%$.

Isolation and identification. Specimens collected from infected patients were processed by conventional methods appropriate to the site of infection. Specimens collected with swabs from colonised patients were inoculated on sheep blood 5\% agar and mannitol salt agar plates. Isolates were identified as $S$. aureus on the basis of colonial morphology, Gram's staining and the results of catalase and coagulase tests [11].

Oxacillin agar screening method. All isolates were plated on Mueller-Hinton agar with $\mathrm{NaCl} 4 \%$ and oxacillin $6 \mathrm{mg} / \mathrm{L}$. The inoculum size was adjusted to deliver a final inoculum of c. $10^{5} \mathrm{cfu} / \mathrm{ml}$. Oxacillin resistance was confirmed by surface growth after incubation for $24 \mathrm{~h}$ at $30^{\circ}-35^{\circ} \mathrm{C}$ [12].

Susceptibility testing. Susceptibility to antimicrobial agents was determined by the agar disk diffusion and agar dilution methods, by the procedures outlined in the Guidelines of the National Committee for Clinical Laboratory Standards (NCCLS) M2-A5 [13] and NCCLS M7-A3 [12], respectively, except for mupirocin [14]. The following antibiotics were used for the agar disk diffusion tests: oxacillin and other $\beta$-lactams, erythromycin, tetracycline, chloramphenicol, clindamycin, ciprofloxacin, trimethoprim-sulphamethoxazole, gentamicin, amikacin, kanamycin, rifampicin, vancomycin and mupirocin. The MIC was determined for three antimicrobial agents: oxacillin, mupirocin and rifampicin. Rifampicin MICs were determined because this antibiotic may be used as an alternative to mupirocin treatment for patients from whom mupirocin-resistant strains are isolated. Isolates with an MIC of $\geqslant 4 \mathrm{mg} / \mathrm{L}$ in $2 \% \mathrm{NaCl}$-supplemented MuellerHinton agar were defined as oxacillin-resistant (MRSA) strains [12]. High-level mupirocin resistance was defined as an MIC of $\geqslant 512 \mathrm{mg} / \mathrm{L}$, and low-level resistance as an MIC of 4-256 mg/L [15]. Rifampicin resistance was defined as an $\mathrm{MIC}$ of $\geqslant 4 \mathrm{mg} / \mathrm{L}$.

Detection of the mecA gene. DNA of MRSA isolates was extracted as described previously [16]. The DNA concentration was determined by spectrophotometry at $260 \mathrm{~nm}$ and adjusted to $200 \mathrm{ng} / \mu 1$ in sterile water. The mecA gene fragment was amplified by the polymerase chain reaction (PCR) with the synthetic oligonucleotide primers MRS1 (5'-TAGAAATGACTG ACGTCCG-3') and MRS2 (5'-TTGCGATCAATGTTACCGTAG-3'), complementary to nucleotides $179-198$ and $312-332$, respectively. The amplification reaction and electrophoresis of the amplified DNA were performed as described previously [17].

$P F G E$. Cells were treated as described previously [18] with the following modifications. Cells were resuspended in $1 \mathrm{M} \mathrm{NaCl}, 10 \mathrm{mM}$ Tris- $\mathrm{HCl}, \mathrm{pH} \mathrm{7.6}$, and mixed with an equal volume of low melting point agarose $2 \%$; lysostaphin $(50 \mu \mathrm{g} / \mathrm{ml})$ was added with lysozyme $(500 \mu \mathrm{g} / \mathrm{ml})$ and proteinase $\mathrm{K}(0.1 \mathrm{mg} / \mathrm{ml})$. The DNA was digested with SmaI (Boehringer Mannheim Corporation, Indianapolis, IN, USA) according to the manufacturer's instructions. The digested agarose plugs were transferred into a 20 -well agarose $1 \%$ gel (Sigma) and electrophoresis was performed with the CHEF-DRII System (BioRad Laboratories, Richmond, CA, USA) at $13^{\circ} \mathrm{C}$ for $21 \mathrm{~h}$ in $0.5 \times \mathrm{TBE}$ buffer ( $40 \mathrm{mM}$ Tris, $1.2 \mathrm{mM}$ boric acid, $40 \mathrm{mM}$ EDTA, $\mathrm{pH} 8.0$ ) at $6 \mathrm{~V} / \mathrm{cm}$. The pulse times were $2 \mathrm{~s}$ (initial) and $35 \mathrm{~s}$ (final). Differences between isolates were determined by visual comparison of the bands and isolates were considered to be related if they differed by no more than three bands [19]. 


\section{Epidemiological methods}

The medical records of patients identified by laboratory surveillance were reviewed for demographic and risk factor data, including age, gender, medical service, clinical diagnosis and underlying illnesses. Risk factor data including preceding antimicrobial therapy, prior hospitalisation, invasive procedures, prior surgery and patient dependency were also recorded. The data were analysed by the Epi Info programme version 5 and differences were analysed statistically by Yates' $\chi^{2}$ tests.

\section{Results \\ Epidemiological data}

In the present study, MRSA isolates were obtained from 62 patients, aged 1-81 years - hospital 1 (43 patients) and hospital 2 (19 patients) (Table 1). Patients at high risk of acquiring MRSA in both hospitals, whether colonised or infected, were adults rather than

Table 1. Clinical and epidemiological characteristics of 62 patients with MRSA at two Brazilian university hospitals

\begin{tabular}{|c|c|c|c|}
\hline \multirow[b]{2}{*}{ Characteristics } & \multicolumn{3}{|c|}{ Number $(\%)$ of patients } \\
\hline & \multicolumn{2}{|c|}{$\begin{array}{l}\text { Hospital } 1 \\
\text { (43 patients) }\end{array}$} & $\begin{array}{c}\text { Hospital } 2 \\
\text { (19 patients) }\end{array}$ \\
\hline \multicolumn{4}{|l|}{ Age (years) } \\
\hline Mean (SD) & \multicolumn{2}{|c|}{$51.5(17.4)$} & $40(19.8)$ \\
\hline Range & \multicolumn{2}{|c|}{$15-81$} & $1-80$ \\
\hline \multicolumn{4}{|l|}{ Prior hospitalisation (days) } \\
\hline Mean & \multicolumn{2}{|l|}{36} & 36 \\
\hline Range & \multicolumn{2}{|c|}{$2-110$} & $2-95$ \\
\hline \multicolumn{4}{|l|}{ Sex } \\
\hline Female & 13 & $(30.0)$ & $6(32.0)$ \\
\hline Male & 30 & $(70.0)$ & $13(68.0)$ \\
\hline \multicolumn{4}{|l|}{ Underlying illness } \\
\hline Diabetes mellitus & 7 & $(16.3)$ & $1 \quad(5.3)$ \\
\hline Cancer & 6 & $(14.0)$ & $3(15.8)$ \\
\hline AIDS & 5 & (11.6) & $1(5.3)$ \\
\hline \multicolumn{4}{|l|}{ Medical service } \\
\hline Medical unit & 18 & $(41.9)$ & $8(42.1)$ \\
\hline Surgical unit & 6 & $(14.0)$ & $8(42.1)$ \\
\hline ITU & 6 & $(14.0)$ & $2(10.5)$ \\
\hline Other & 13 & $(30.2)$ & $1 \quad(5.3)$ \\
\hline \multicolumn{4}{|l|}{ Clinical diagnosis } \\
\hline Respiratory tract infection & 11 & $(25.6)$ & $5(26.3)$ \\
\hline Surgical site infection & 8 & $(18.6)$ & $7(36.8)$ \\
\hline Bloodstream infection & 8 & (18.6) & $2(10.5)$ \\
\hline Other & 16 & $(37.2)$ & $5(26.3)$ \\
\hline Preceding antibiotic therapy & 36 & $(83.7)$ & $13(68.4)$ \\
\hline \multicolumn{4}{|l|}{ Antibiotic therapy } \\
\hline$\beta$-Lactams & 24 & $(43.7)$ & $6(26.1)$ \\
\hline Aminoglycosides & 13 & $(23.0)$ & $6(26.1)$ \\
\hline Macrolides & 5 & $(9.1)$ & $6(26.1)$ \\
\hline Quinolones & 6 & $(10.9)$ & $2(8.7)$ \\
\hline Other & 7 & (12.7) & $3(13.0)$ \\
\hline Recent surgery & 15 & (34.9) & $9(47.4)$ \\
\hline Hospitalisation ( $>7$ days) & 41 & $(95.3)$ & $18(94.7)$ \\
\hline Invasive procedures & 33 & $(76.7)$ & $16(84.2)$ \\
\hline Patient restricted to bed & 35 & $(81.4)$ & $17(89.5)$ \\
\hline
\end{tabular}

Hospital 1, Rio de Janeiro Federal University Hospital, Rio de Janeiro, Brazil; hospital 2, Uberlândia Federal University Hospital, Uberlândia, Minas Gerais, Brazil. children, with a preponderance of males $(70 \%)$. Other associated risk factors for MRSA acquisition included hospitalisation for $>7$ days ( 59 cases, $95 \%$ ), patient restriction to bed ( 52 cases, $84 \%$ ), invasive procedures (49 cases, $79 \%$ ) and preceding antimicrobial therapy (49 cases, $79 \%$ ).

The recent administration of $\beta$-lactam antibiotics was common (48\%), and cancer (14\%) and diabetes mellitus $(13 \%)$ were the most frequent underlying illnesses associated with MRSA infections. Respiratory tract infection was the most frequently diagnosed infection (16 cases, 26\%), followed by surgical site infections (15 cases, $24 \%$ ) and bloodstream infections (10 cases, 16\%).

The majority of the MRSA infections were isolated from medical units $(48 \%)$ in both hospitals, but the data analysed by the Epi Info programme demonstrated no significant statistical differences $(p>0.05)$ for clinical or epidemiological characteristics.

\section{Susceptibility to antimicrobial agents}

One hundred and three MRSA isolates were analysed, 59 strains from hospital 1 and 44 strains from hospital 2 (Table 2). All MRSA isolates were also resistant to gentamicin and kanamycin. The majority were also resistant to erythromycin (99\%), tetracycline $(99 \%)$, sulphamethoxazole-trimethoprim (98\%), clindamycin (96\%), ciprofloxacin $(96 \%)$, amikacin $(95 \%)$, chloramphenicol $(85 \%)$ and rifampicin $(73 \%)$, rendering these antibiotics ineffective as therapy against MRSA. Resistance to vancomycin was not observed. However, some variability in resistance patterns according to the origin of the strain was noted: $32 \%$ of isolates in hospital 1 were susceptible only to vancomycin; in hospital 2, $48 \%$ of strains were vancomycin- and mupirocin-susceptible, and $34 \%$ were susceptible to vancomycin, mupirocin and chloramphenicol.

MIC results revealed that all MRSA strains were resistant to high concentrations of oxacillin (MIC $\geqslant 512 \mathrm{mg} / \mathrm{L}$ ). Rifampicin resistance (MIC $\geqslant 4 \mathrm{mg} / \mathrm{L}$ ) was observed in $54 \%$ of the strains isolated in Rio de Janeiro (hospital 1), and in $98 \%$ of the Uberlândia strains (hospital 2). Forty (39\%) of all MRSA isolates were mupirocin-resistant and the proportion in hospital 1 was significantly higher than in hospital $2(p<$ 0.001) (Table 3). High-level mupirocin resistance $(\mathrm{MIC} \geqslant 512 \mathrm{mg} / \mathrm{L})$ was seen in 27 isolates and 13 isolates showed low-level resistance (MIC 4$256 \mathrm{mg} / \mathrm{L}$ ).

\section{Genotypic characterisation}

Analysis of mec A gene. All MRSA isolates carried $m e c \mathrm{~A}$ in their genome resulting in a 154-bp fragment, 
Table 2. Susceptibility to antimicrobial agents and chromosomal DNA PFGE patterns of 103 MRSA isolates from two Brazilian university hospitals

\begin{tabular}{|c|c|c|c|c|c|}
\hline \multirow[b]{2}{*}{ Hospital } & \multicolumn{2}{|c|}{ PFGE } & \multirow[b]{2}{*}{$\begin{array}{l}\text { Antibiotic susceptibility pattern* } \\
\text { (number of isolates) }\end{array}$} & \multicolumn{2}{|c|}{$\mathrm{MIC}^{\dagger}$ (mg/L) (range) } \\
\hline & $\begin{array}{l}\text { Number of } \\
\text { isolates }\end{array}$ & Pattern & & RIF & MUP \\
\hline 1 & 9 & $A_{1}$ & VC (7); VC, MUP, RIF (2) & $2-\geqslant 512$ & $1-\geqslant 512$ \\
\hline \multirow[t]{8}{*}{ (59 isolates) } & 37 & $\mathrm{~A}_{2}$ & $\begin{array}{l}\text { VC (11); VC, MUP (5); VC, RIF (6); VC, MUP, } \\
\text { RIF (11); VC, AM (2); VC, AM, MUP (1); VC, } \\
\text { CO (1) }\end{array}$ & $1-\geqslant 512$ & $1-\geqslant 512$ \\
\hline & 4 & $\mathrm{~A}_{3}$ & VC, RIF (3); VC, CO, TC, CIP, CL, MUP (1) & $1-\geqslant 512$ & $1-\geqslant 512$ \\
\hline & 2 & $\mathrm{~A}_{4}$ & VC, RIF & 2 & 32 \\
\hline & 3 & B & VC, RIF (2); VC, MUP (1) & $2-\geqslant 512$ & $2-\geqslant 512$ \\
\hline & 1 & $\mathrm{C}$ & VC, RIF & 1 & $\geqslant 512$ \\
\hline & 1 & I & $\mathrm{VC}$ & 4 & 32 \\
\hline & 1 & $\mathrm{~J}_{1}$ & VC, TS, MUP, AM, CIP & $\geqslant 512$ & 1 \\
\hline & 1 & $\mathrm{~J}_{2}$ & VC, TS, MUP, AM, CIP, CL & $\geqslant 512$ & 1 \\
\hline 2 & 24 & $A_{1}$ & VC, MUP (18); VC (2); VC, MUP, CO (4); & $4-\geqslant 512$ & $2-\geqslant 512$ \\
\hline \multirow[t]{7}{*}{ (44 isolates) } & 6 & $\mathrm{~A}_{5}$ & VC, MUP, CO (5); VC, MUP (1) & $8-\geqslant 512$ & 2 \\
\hline & 6 & B & VC, MUP, CO (6) & $8-\geqslant 512$ & 2 \\
\hline & 1 & $\mathrm{D}$ & $\mathrm{VC}$ & 64 & 4 \\
\hline & 2 & $\mathrm{E}$ & VC, MUP, CL & $\geqslant 512$ & 2 \\
\hline & 2 & $\mathrm{~F}$ & VC, MUP, CIP, AM & 4 & 2 \\
\hline & 2 & $\mathrm{G}$ & VC, MUP & 4 & 2 \\
\hline & 1 & $\mathrm{H}$ & VC, MUP, RIF, AM, TC, EI & 2 & 2 \\
\hline
\end{tabular}

* Number of strains susceptible to the antimicrobial indicated. VC, vancomycin; MUP, mupirocin; RIF, rifampicin; EI, erythromycin; TC, tetracycline; CO, chloramphenicol; CL, clindamycin; CIP, ciprofloxacin; TS, trimethoprim-sulphamethoxazole; AM, amikacin.

${ }^{\dagger}$ All strains were oxacillin-resistant $(\mathrm{MIC} \geqslant 512 \mu \mathrm{g} / \mathrm{ml}$ ).

Table 3. Characteristics of mupirocin-resistant MRSA isolates in two Brazilian university hospitals

\begin{tabular}{lccccc}
\hline & \multicolumn{2}{c}{ PFGE } & & \multicolumn{2}{c}{ Mupirocin resistance (number of isolates) } \\
\cline { 2 - 3 } \cline { 5 - 6 } Hospital & $\begin{array}{c}\text { Number of } \\
\text { isolates }\end{array}$ & Pattern & & $\begin{array}{c}\text { low-level } \\
\text { (MIC } \geqslant 4-\leqslant 256)\end{array}$ & $\begin{array}{c}\text { high-level } \\
(\mathrm{MIC} \geqslant 512)\end{array}$ \\
\hline 1 & 7 & $\mathrm{~A}_{1}$ & & 5 & 2 \\
$(37$ isolates $)$ & 23 & $\mathrm{~A}_{2}$ & & 3 & 1 \\
& 3 & $\mathrm{~A}_{3}$ & & 2 & 0 \\
& 1 & $\mathrm{~A}_{4}$ & & 1 & 1 \\
& 1 & $\mathrm{~B}$ & & 0 & 0 \\
2 & 1 & $\mathrm{C}$ & & 0 & 2 \\
(3 isolates) & 1 & $\mathrm{I}$ & & 1 & 0 \\
Total & 2 & $\mathrm{~A}_{1}$ & & 0 & 27 \\
\hline
\end{tabular}

after PCR amplification (Fig. 1); this pattern is typical of all MRSA isolates.

PFGE. Among the 103 isolates, 10 PFGE patterns were observed. A predominant pattern (type A) was found among strains isolated in both hospitals (Table 2 and Fig. 2). Five PFGE types were identified among the isolates from hospital 1 (A, B, C, I and J types), and seven PFGE types were found among isolates in hospital 2 (A, B, D, E, F, G and $\mathrm{H}$ types). PFGE type A appeared to be widespread in both hospitals $(80 \%$ of all isolates: $88 \%$ in hospital 1 and $68 \%$ in hospital 2) and five distinct subtypes were detected. Four of these patterns were identified in hospital $1\left(\mathrm{~A}_{1}, \mathrm{~A}_{2}, \mathrm{~A}_{3}\right.$ and $A_{4}$ subtypes) and two subtypes were seen in hospital 2 $\left(A_{1}\right.$ and $\left.A_{5}\right)$. The subtype $A_{2}$ was identified in $63 \%$ of the isolates from hospital 1 ; subtype $A_{1}$ was more frequent in hospital $2(54 \%)$. Subtypes $A_{1}$ was isolated at both hospitals. Ninety percent of the mupirocinresistant isolates belonged to PFGE pattern A.

The majority of nosocomial cases at both hospitals were epidemiologically related, according to the time of occurrence, medical service and PFGE type and subtypes. PFGE type A was isolated from all medical services in both hospitals and was more common than in other units, i.e., $41 \%$ of isolates from hospital 1 and $32 \%$ of isolates from hospital 2. Strains belonging to other PFGE patterns were isolated from six patients in hospital 1 (B, C, I and J clonal types) and were not epidemiologically related. In hospital 2, 14 isolates of other types (B, D, E, F, G and H types) were obtained from eight patients, 6 of which were simultaneously infected or colonised with distinct PFGE types at different body sites. For example, PFGE type G strain was simultaneously isolated from 


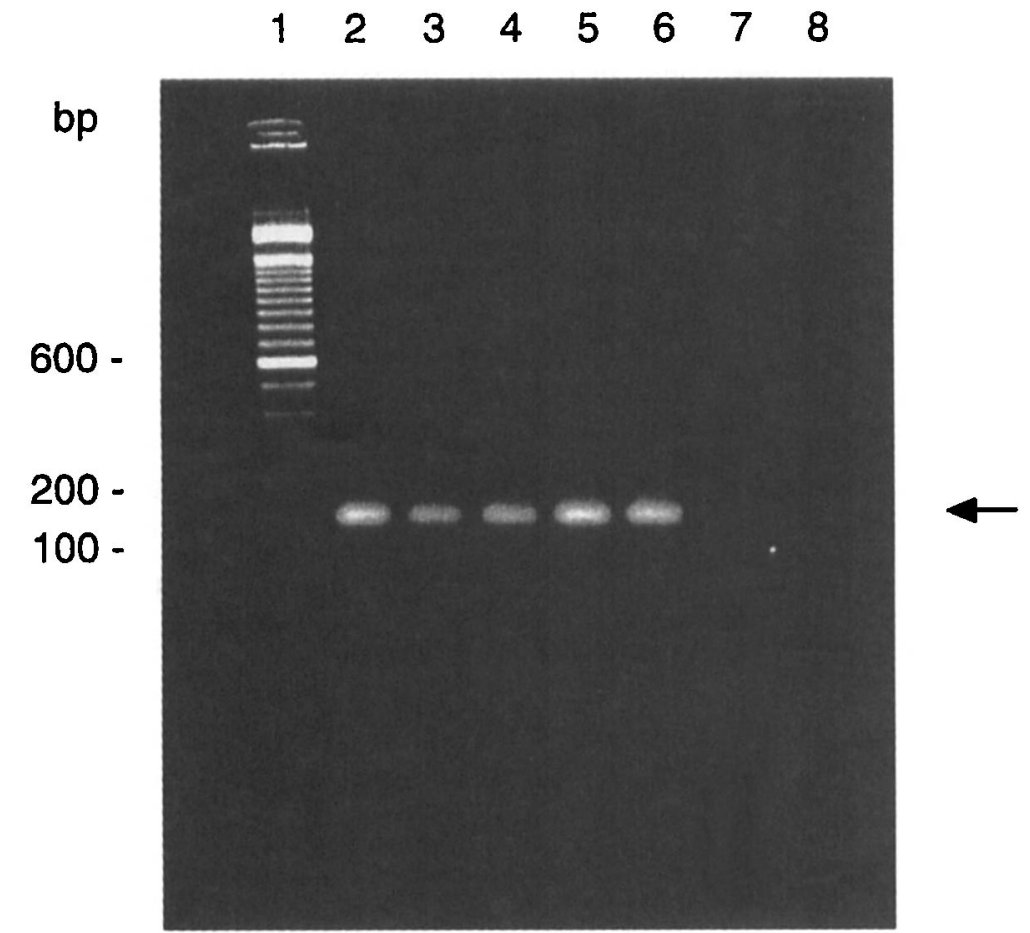

Fig. 1. Agarose gel electrophoresis of the 154-bp amplified DNA fragment corresponding to the mecA gene. Lane 1, DNA size marker (100-bp ladder); 2-6, MRSA isolates; 7, negative control methicillin-susceptible $S$. aureus strain; 8, PCR negative control.

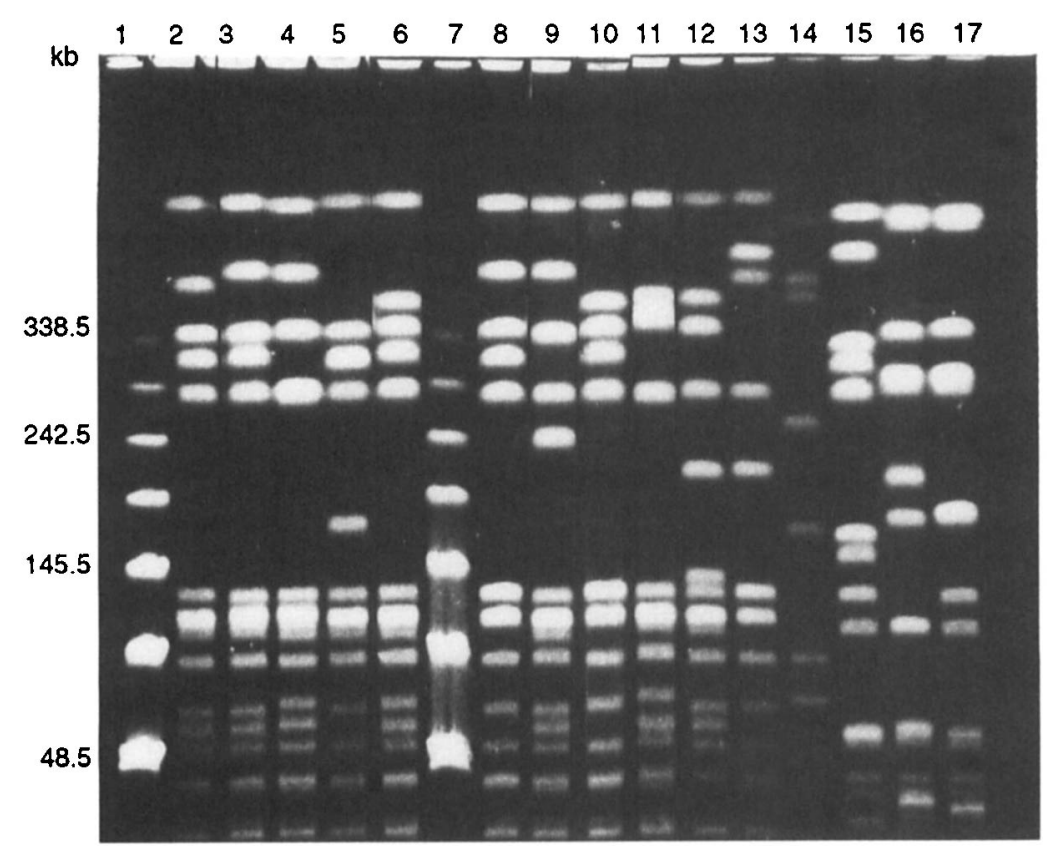

Fig. 2. PFGE patterns of Sma I-digested chromosomal DNA from MRSA strains isolated in two Brazilian university hospitals. Lanes 1 and 7, DNA size marker; 2-6, subtype A strains $\left(A_{1}-A_{5}\right) ; 8-17$, additional types $(B, C, D, E, F, G$, $\mathrm{H}, \mathrm{I}, \mathrm{J}_{1}, \mathrm{~J}_{2}$ ).

the bloodstream and nares of one patient, while a PFGE type B strain was isolated from the rectum of this patient. In another patient PFGE type $\mathrm{H}$ was isolated from the rectum and PFGE type B from a surgical site.

\section{Discussion}

The clinical features of the patients reported here resemble those described in previous reports $[6,20]$. In the present study, patients colonised and infected with 
MRSA were seriously ill, required prolonged hospitalisation (with a mean duration of 36 days) and had received previous antimicrobial chemotherapy with $\beta$ lactams and aminoglycosides. Previous hospitalisation is usually associated with diseases that have a chronic course or with previous underlying diseases and this was the most frequent risk factor associated with MRSA infection in the present study, as has seen reported by others $[2,5,6,20]$. Antimicrobial chemotherapy with $\beta$-lactams and aminoglycosides is associated with an increased risk of acquiring MRSA in hospitals [20]. Invasive procedures represent 'entrance gates' for micro-organisms, that contaminate the hands of health care personnel who perform procedures and, therefore, increase the risk of MRSA transmission; this risk factor was observed in $79 \%$ of the patients in a previous study [6]. Issa et al. [7] observed that patients restricted to bed might be at high risk for acquiring MRSA infection or colonisation because these patients are more likely to be in frequent contact with health care personnel, as these patients are more dependent. In the present study, this risk factor for MRSA infection or colonisation was observed in $84 \%$ of cases. These results show that documenting risk factors may help in the identification of patients at higher risk for MRSA infection or colonisation.

Antimicrobial susceptibility testing is routinely performed by clinical microbiology laboratories on most bacterial isolates. The identification of new or unusual patterns of antibiotic resistance among bacteria isolated from various patients may raise the suspicion of an outbreak or the presence of a new strain [21]. However, antibiotic susceptibility testing has relatively limited use in epidemiological studies because of phenotypic variation, and because antibiotic resistance is affected by selective pressure in hospitals [22]. In this report, strains with different PFGE patterns had similar antibiotic susceptibility patterns, and clinical isolates of the same PFGE pattern were found to exhibit different antibiotic susceptibility patterns (Table 2). Thus, the relationship between antibiotic susceptibility and PFGE patterns was not close. The results revealed considerable variability of antibiotic resistance to chloramphenicol and mupirocin.

Mupirocin has become the topical agent of choice for the elimination of MRSA carriage. However, numerous studies have shown that the widespread use of mupirocin is associated with increasing resistance $[23,24]$. With the continuing emergence of both highand low-level mupirocin resistance, accurate strain classification is important for hospital epidemiology. The data from the present study show that 39\% (40 of 103) of the MRSA isolates were mupirocin-resistant and $90 \%$ of them belonged to epidemic PFGE type A. Furthermore, $93 \%$ of strains showing high-level mupirocin resistance belonged to three distinct subtypes of PFGE type A (Table 3). This is of special concern, as the nosocomial spread of a single strain with high-level mupirocin resistance reduces the usefulness of topical intranasal mupirocin as a control measure in hospitals [25].

A further problem in control and prevention is that certain body sites colonised by MRSA, such as wounds, secretions from tracheostomies and the oropharynx, are particularly resistant to efforts at eradication [26], which increases the risk of spread. Patients with persistent nasal carriage may be colonised on their hands or other body sites and disperse the organism into the surrounding environment [25]. In the present study $61 \%$ of strains were isolated from colonisation sites $-37 \%$ from the anterior nares and $24 \%$ from other sites, including skin lesions, tracheostomy, sputum, rectum and perineum. Patients colonised for prolonged periods may act as a source of spread to other patients by direct contact. An additional point is that many patients are colonised at multiple sites and so carriage will be missed if only one site is sampled [26]. Furthermore, MRSA may persist in the environment and become an endemic source of infection in the institution.

The molecular characterisation of all MRSA isolates collected between Sept. 1994 and Sept. 1995 showed a predominance of a single PFGE pattern (type A) in both hospitals. The occurrence of this epidemic type among Brazilian MRSA strains was described previously by Sader et al. [27] in hospitals in São Paulo, Brazil. Strains with PFGE patterns similar to chromosomal DNA pattern A were also shown to be the most frequent among MRSA isolates from 16 hospitals in six cities located in the north and south of Brazil [28]. However, strains from the city of Uberlândia have not been characterised in previous studies. It is not clear which feature of this particular clone of MRSA leads to its predominance and continued prevalence in the hospital environment. A virulence-related property may exist in this clone, increasing adherences resulting in colonisation and infection, as has been reported for other epidemic clones [29].

A comparison of the PFGE patterns of the isolates (Fig. 2) allowed the identification of genetic similarities, except for $\mathrm{H}, \mathrm{I}$ and $\mathrm{J}$ types. The PFGE types B-G showed differences of four to six bands when compared with PFGE type A. These differences can be explained by simple insertions or deletions of DNA or the gain or loss of restriction sites [19]. These strains were considered to be possibly related to the epidemic clone type $\mathrm{A}$, suggesting that the isolates may be derived from a common source. On the other hand, isolates belonging to identical types were obtained from epidemiologically unrelated patients at both hospitals. Although PFGE has a very high discriminatory power and even distinguishes subclones, it does not discriminate epidemiologically unrelated MRSA strains. Maslow et al. [22] reported 
that for pathogens, such as MRSA, representing genetically restricted subsets of strains within a species, less variation is detected among unrelated isolates, as many isolates are derived from a limited number of genomically distinct clones. Sader et al. [27] suggested digestion with a second enzyme or the use of PFGE with another molecular typing method to detect differences among nosocomial isolates of the same predominant type from patients who are not epidemiologically related.

PFGE typing and other typing methods are crucial in confirming the efficacy of MRSA control in hospitals. Single-bed or cohort nursing together with regular educational programmes to motivate handwashing by health care workers have been found to be effective in controlling nosocomial MRSA infection [5, 8]. Specific control measures should be directed aggressively to identify patients at higher risk or to reduce antimicrobial pressure within institutions. The recent emergence of MRSA clinical strains with reduced vancomycin susceptibility [30] reinforces the importance of these control measures within institutions.

\section{References}

1. Wenzel RP, Nettleman MD, Jones RN, Pfaller MA. Methicillinresistant Staphylococcus aureus: implications for the 1990s and effective control measures. Am $J$ Med 1991; 91 Suppl 3B: 221S-227S

2. Boyce JM. Methicillin-resistant Staphylococcus aureus in hospitals and long-term care facilities: microbiology, epidemiology, and preventive measures. Infect Control Hosp Epidemiol 1992; 13: 725-737.

3. Emori TG, Gaynes RP. An overview of nosocomial infections, including the role of the microbiology laboratory. Clin Microbiol Rev 1993; 6: 428-442.

4. Pannuti CS, Grinbaum RS. An overview of nosocomial infection control in Brazil. Infect Control Hosp Epidemiol 1995; 16: 170-174.

5. Meier PA, Carter CD, Wallace SE, Hollis RJ, Pfaller MA, Herwaldt LA. A prolonged outbreak of methicillin-resistant Staphylococcus aureus in the burn unit of a tertiary medical center. Infect Control Hosp Epidemiol 1996; 17: 798-802.

6. Asensio A, Guerrero A, Quereda C, Lizán M, Martinez-Ferrer M. Colonization and infection with methicillin-resistant Staphylococcus aureus: associated factors and eradication. Infect Control Hosp Epidemiol 1996; 17: 20-28.

7. Issa L, Marangoni DV, Moreira BM, Schirmer MR, Suassuna I. Prevalência de pacientes de risco e percentual de isolamentos de MRSA em 'swab' nasal neste grupo de pacientes de setembro de 1990 a setembro de 1993 no HUCFF. 1st South West Brazilian Congress on the Control of Hospitalar Infection, 16-19 November, 1993.

8. Hartstein AI, LeMonte AM, Iwamoto PKL. DNA typing and control of methicillin-resistant Staphylococcus aureus at two affiliated hospitals. Infect Control Hosp Epidemiol 1997; 18: 42-48.

9. Saulnier P, Bourneix C, Prévost G, Andremont A. Random amplified polymorphic DNA assay is less discriminant than pulsed-field gel electrophoresis for typing strains of methicillinresistant Staphylococcus aureus. J Clin Microbiol 1993; 31: 982-985.

10. Prévost G, Jaulhac B, Piemont Y. DNA fingerprinting by pulsed-field gel electrophoresis is more effective than ribotyping in distinguishing among methicillin-resistant Staphylococ- cus aureus isolates, $J$ Clin Microbiol 1992; 30: 967-973.

11. Kloos WE, Bannerman TL. Staphylococcus and Micrococcus. In: Murray PR, Baron EJ, Pfaller MA, Tenover FC, Yolken RH. Manual of clinical microbiology, 6th edn. Washington, DC, American Society for Microbiology Press. 1995.

12. National Committee for Clinical Laboratory Standards. Approved Standard. Methods for dilution antimicrobial susceptibility tests for bacteria that grow aerobically, 3rd edn. Villanova, PA, NCCLS. Approved standard: M7-A3.NCCLS. 1993.

13. National Committee for Clinical Laboratory Standards. Performance standards for antimicrobial disk susceptibility tests, 5th edn. Villanova, PA, NCCLS. Approved standard: M2-A5. 1993.

14. Fuchs PC, Jones RN, Barry AL. Interpretative criteria for disk diffusion susceptibility testing of mupirocin, a topical antibiotic. J Clin Microbiol 1990; 28: 608-609.

15. Eltringham I. Mupirocin resistance and methicillin-resistant Staphylococcus aureus (MRSA). J Hosp Infect 1997; 35: 1-8.

16. Welsh J, McClelland M. Fingerprinting genomes using PCR with arbitary primers. Nucleic Acids Res 1990; 18: 7213-7218.

17. Del Vechio VG, Petroziello JM, Gress MJ et al. Molecular genotyping of methicillin-resistant Staphylococcus aureus via fluorophore-enhanced repetitive-sequence PCR. J Clin Microbiol 1995; 33: 2141-2144.

18. Jorgensen $M$, Givney R, Pegler M, Vickery A, Funnell G. Typing multidrug-resistant Staphylococcus aureus: conflicting epidemiological data produced by genotypic and phenotypic methods clarified by phylogenetic analysis. J Clin Microbiol 1993; 34: 398-403.

19. Tenover FC, Arbeit RD, Goering RV et al. Interpreting chromosomal DNA restriction patterns produced by pulsedfield gel electrophoresis: criteria for bacterial strain typing. $J$ Clin Microbiol 1995; 33: 2233-2239.

20. Pujol M, Peña C, Pallares R, Ayats J, Ariza J, Gudiol F. Risk factors for nosocomial bacteremia due to methicillin-resistant Staphylococcus aureus. Eur J Clin Microbiol Infect Dis 1994; 13: 96-102.

21. Udo EE, Al-Obaid IA, Jacob LE, Chugh TD. Molecular characterization of epidemic ciprofloxacin- and methicillinresistant Staphylococcus aureus strains colonizing patients in an intensive care unit. J Clin Microbiol 1996; 34: 3242-3244.

22. Maslow JN, Mulligan ME, Arbeit RD. Molecular epidemiology: application of contemporary techniques to the typing of microorganisms. Clin Infect Dis 1993; 17: 153-164.

23. Udo EE, Perman JR, Grubb WB. Emergence of highlevel mupirocin resistance in methicillin-resistant Staphylococcus aureus in western Australia. J Hosp Infect 1994; 26: 157-165.

24. Netto dos Santos KR, De Sousa Fonseca L, Gontijo Filho PP. Emergence of high-level mupirocin resistance in methicillinresistant Staphylococcus aureus isolated from Brazilian university hospitals. Infect Control Hosp Epidemiol 1996; 17: $813-816$.

25. Boyce JM. Preventing staphylococcal infections by eradicating nasal carriage of Staphylococcus aureus: proceeding with caution. Infect Control Hosp Epidemiol 1996; 17: 775-779.

26. Mylotte JM. Control of methicillin-resistant Staphylococcus aureus: the ambivalence persists. Infect Control Hosp Epidemiol 1994; 15 73-77.

27. Sader HS, Pignatari AC, Hollis RJ, Jones RN. Evaluation of interhospital spread of methicillin-resistant Staphylococcus aureus in São Paulo, Brazil, using pulsed-field gel electrophoresis of chromosomal DNA. Infect Control Hosp Epidemiol 1994; 15: 320-323.

28. Teixeira LA, Resende CA, Ormonde LR et al. Geographic spread of epidemic multiresistant Staphylococcus aureus clone in Brazil. $J$ Clin Microbiol 1995; 33: 2400-2404.

29. Tomasz A. Benefit and risk in the $\beta$-lactam antibiotic-resistance strategies of Streptococcus pneumoniae and Staphylococcus aureus. Trends Microbiol 1994; 2: 380-385.

30. Hiramatsu K, Hanaki H, Ino T, Yabuta K, Oguri T, Tenover FC. Methicillin-resistant Staphylococcus aureus clinical strain with reduced vancomycin susceptibility. $J$ Antimicrob Chemother 1997; 40: 135-136. 